\title{
ANTIFUNGAL POTENTIAL OF ETHANOL EXTRACTS OF ALLIUM SATIVUM AND ALLIUM AMPELOPRASUM
}

\author{
SHAHID KHAN, NEETA RAJ SHARMA*
}

Department of Biotechnology, School of Bioengineering and Biosciences, Lovely Professional University, Phagwara, Punjab, India. Email: neeta.raj@lpu.co.in

Received: 11 December 2016, Revised and Accepted: 31 December 2016

\section{ABSTRACT}

Objective: In vitro analysis of Allium sativum and Allium ampeloprasum was performed to evaluate their antifungal potential against Alternaria triticina (ITCC 5496), causative agent of leaf blight in wheat and Magnaporthe oryzae (ITCC 6808), causative agent of blast disease in rice.

Methods: Ethanol extracts of $A$. ampeloprasum and $A$. sativum were prepared by crushing their bulb in liquid nitrogen and then immersing them in $90 \%$ ethanol and $100 \%$ ethanol separately. The antifungal activity test was determined by quantitative assay using 96 -well microtiter plate, and results were statistically analyzed using GraphPad Prism v. 5.03.

Results: A. triticina and M. oryzae showed above $90 \%$ and 95\% growth inhibition, respectively, against the ethanol extracts of A. ampeloprasum. Conversely, growth inhibition of either fungus remained mostly below $35 \%$ against ethanol extracts of $A$. sativum at all tested concentrations.

Conclusion: Ethanol extracts of A. ampeloprasum have relatively higher antifungal potential than ethanol extracts of $A$. sativum and could be considered as a natural alternative to chemical fungicides.

Keywords: Ethanol extract, antifungal, Allium sativum, Allium ampeloprasum, Alternaria triticina, Magnaporthe oryzae.

(C) 2017 The Authors. Published by Innovare Academic Sciences Pvt Ltd. This is an open access article under the CC BY license (http://creativecommons. org/licenses/by/4. 0/) DOI: http://dx.doi.org/10.22159/ajpcr.2017.v10i4.16555

\section{INTRODUCTION}

Allium sativum (garlic) is known for its antimicrobial properties including antibacterial, antifungal, antiprotozoal, and insecticidal properties [1]. Crude extracts of $A$. sativum were tested against the laboratory isolate of Candida albicans [2] and are referred as broadspectrum antimycotic agents [3]. Allicin, an active component of garlic, found in water and ethanol extracts of A. sativum [4], is often reported for its effective antifungal properties in many research articles, such as, against Candida, Cryptococcus, Trichophyton, Microsporum, and Epidermophyton [5]. Ajoene, another compound derived from ethanol extracts of $A$. sativum is also reported as an excellent antifungal agent, when tested against Aspergillus niger, C. albicans and Paracoccidioides brasiliensis [6]. Despite its remarkable antifungal potential, A. sativum is neither preferred in agricultural field for protecting crops from pathogens nor as a food preservative; because, of its strong odor [7]

Conversely, Allium ampeloprasum (elephant garlic) has a much milder flavor and is less pungent than A. sativum [8]. It is known to be more beneficial than other Allium species [9]. Essential oil of A. ampeloprasum showed inhibitory effect on Rhodotorula sp. and Saccharomyces cerevisiae [10]. Cinnamic acid derivatives of A. ampeloprasum were reported to possess antifungal potency against $A$. niger, Penicillium italicum, Botrytis cinerea, and Trichoderma harzianum [11].

The fungal strains used in this study are Alternaria triticina and Magnaporthe oryzae, fungal phytopathogens of wheat and rice, respectively. A. triticina (phylum Ascomycetes) causes leaf blight disease which results in high yield losses and severe infection in wheat and barley [12]. While investigating the most prevalent foliar blight pathogens in India, A. triticina was reported as the second most frequent phytopathogen [13]. On the other hand, M. oryzae (phylum Ascomycetes) is rated at first place among the list of top 10 most harmful fungal phytopathogens [14]. It causes rice blast disease which is a predominant biotic stress, affecting the rice production worldwide [15]. Although the chief host of this fungus is rice, it is also reported to infect wheat causing wheat blast disease [16].

Ethanol extracts of numerous medicinal plants are often reported for their antifungal properties in many researches [17-19]. Ethanol extracts of $A$. sativum are known to show a significant inhibitory effect against A. niger, Aspergillus ustus, C. albicans, Fusarium oxysporum, Metschnikowia fructicola, and Penicillium species [7,20,21]. Ethanol extracts of $A$. ampeloprasum are not yet reported for their antifungal properties. This study was primarily undertaken to evaluate the antifungal properties of ethanol extracts of $A$. ampeloprasum. Further, the ethanol extracts of $A$. ampeloprasum were studied in contrast to the ethanol extracts of $A$. sativum, against two extremely harmful cereal crop pathogens, viz., A. triticina and M. oryzae, to study their potential as antifungal agents and to develop an efficient antifungal formulation.

\section{MATERIALS AND METHODS}

\section{Biological material}

A. sativum (garlic) and A. ampeloprasum (elephant garlic) garlic species were obtained from Dosanjh Agricultural Research and Development Farm, Punjab. Pure cultures of A. triticina (ITCC 5496) and M. oryzae (ITCC 6808) were used in this study.

\section{Maintenance of fungal culture and spore isolation}

Pure cultures were refreshed and maintained on potato dextrose agar slants and plates on regular basis. The cultures were streaked on sterile potato dextrose agar plates and kept in incubator at $27^{\circ} \mathrm{C}$ for 5-10 days depending on the growth rate of each fungus, once grown they were stored at $4^{\circ} \mathrm{C}$. Fungal cultures were refreshed twice a month to avoid contamination. Spores were isolated from the cultures grown on potato dextrose agar plates and stored at $4{ }^{\circ} \mathrm{C}$ in a sterile test tube [22] 
Preparation of ethanol extracts

Bulb of both the garlic species was first washed with tap water followed by distilled water thoroughly. They were ground to fine powder in liquid nitrogen using mortar and pestle and stored carefully at $-20^{\circ} \mathrm{C}$. $25 \mathrm{~g}$ of powdered material from each species was soaked in $50 \mathrm{ml}$ of $90 \%$ ethanol and $100 \%$ ethanol separately and was kept at room temperature for 24 hrs; further, they were filtered using Whatman No. 1 filter paper. The filtrate was heated at $35-45^{\circ} \mathrm{C}$ using water bath, to completely remove any residues of ethanol and obtain dried powder. It was then weighed and dissolved in equal amount of distilled water to obtain $1 \mathrm{~g} / \mathrm{ml}$ concentration of ethanol extracts. These extracts were stored in the form of aliquots at $4^{\circ} \mathrm{C}$ for further testing

\section{Antifungal activity}

The antifungal activity test was performed by quantitative assay [22] with little modifications. Growth inhibition was measured in sterile 96-well microtiter plate arranged in eight series A to $\mathrm{H}$, each one with 12 wells numbered 1 through 12 . Potato dextrose broth was used as medium to support the growth of fungal spores and also as a medium to make extract and spore suspension. Fungal spores were suspended in PDB and spore count was optimized to $2 * 10^{6}$ spores $/ \mathrm{ml}$, likewise, ethanol extract was also brought up to a concentration of $200 \mu \mathrm{g} / \mathrm{ml}$ of PDB from an initial concentration of $1 \mathrm{~g} / \mathrm{ml}$ of water. $200 \mu \mathrm{l}$ of extract suspension was added in all wells of series A, rest of the plate was filled with $100 \mu \mathrm{l}$ of PDB. Now $100 \mu \mathrm{l}$ of extract suspension from series A was added to series B and so on till series $G$ to make dilutions in subsequent wells, remaining $100 \mu \mathrm{l}$ extract suspension was discarded from series G. Add $100 \mu \mathrm{l}$ of spore suspension in the first three wells of all the series and $100 \mu \mathrm{l}$ of PDB in next three wells of all the series to provide dilutions of ethanol extract ranging from $100 \mu \mathrm{g} / \mathrm{ml}$ to $1.5625 \mu \mathrm{g} / \mathrm{ml}$ in series $\mathrm{A}$ to $\mathrm{G}$, respectively, leaving series $\mathrm{H}$ as control. The first three wells of each series from $A$ to $G$ was referred as test and the next three wells as test blank, similarly first three wells of series $\mathrm{H}$ were referred as control and the next three wells as control blank. Remaining six wells of each series could be used to test another ethanol extract while following the pattern mentioned earlier. All tests were carried out in triplicates. Titer plates were covered with lid, sealed using parafilm, and kept at $27^{\circ} \mathrm{C}$ in B.O.D. incubator for $48 \mathrm{hrs}$ after which readings were taken at $595 \mathrm{~nm}$ using Microplate reader (Biorad).

Calculation for percentage growth inhibition, minimal inhibitory concentration (MIC ${ }_{50}$ ) and MIC $_{90}$

Percentage growth inhibition was determined based on the equation $([\Delta \mathrm{C}-\Delta \mathrm{T}] / \Delta \mathrm{C})^{*} 100$ where, $\Delta \mathrm{C}$ is the average absorbance of the control microculture minus the average absorbance of control blank and $\Delta \mathrm{T}$ is the average absorbance of the test microculture minus the average absorbance of test blank [23]. Growth inhibition was presented in the form of (mean \pm standard deviation [SD]) \%, where SD is the standard deviation. $\mathrm{MIC}_{50}$ and $\mathrm{MIC}_{90}$ values were determined using the graphing software Graph v. 4.4.2 for the ethanol extracts that showed greater antifungal activity. Minimum concentration of ethanol extract showing $50 \%$ and $90 \%$ growth inhibition were considered as $\mathrm{MIC}_{50}$ and $\mathrm{MIC}_{90}$ values, respectively.

\section{Statistical analysis}

Two-way analysis of variance (ANOVA) was performed to measure the significant difference among the different concentrations of the ethanol extracts against percentage growth inhibition, due to the effect of the ethanol extracts on each fungus. The data were gathered and were statistically analyzed using statistical software GraphPad Prism v. 5.03 at $95 \%$ confidence interval.

\section{RESULT AND DISCUSSION}

Test results showed that the maximum growth inhibition of $A$. triticina occurred by $100 \%$ ethanol extract of A. ampeloprasum, while other extracts showed less than $40 \%$ growth inhibition at all tested concentration. Lowest growth inhibition of $(0.6 \pm 0.3) \%$ was shown by $100 \%$ ethanol extract of $A$. sativum at $3.125 \mu \mathrm{g} / \mathrm{ml}$ concentration, although it showed growth inhibition of $(21.3 \pm 0.4) \%$ at a concentration of $12.5 \mu \mathrm{g} / \mathrm{ml}$. $90 \%$ ethanol extract of A. sativum also showed low antifungal activity, with a minimum growth inhibition of $(9.2 \pm 0.3) \%$ at a concentration of $12.5 \mu \mathrm{g} / \mathrm{ml}$ and maximum growth inhibition of $(12.5 \pm 0.3) \%$ at $1.5625 \mu \mathrm{g} / \mathrm{ml}$ concentration. Similarly, $90 \%$ ethanol extract of A. ampeloprasum also showed low antifungal activity against $A$. triticina showing $15-32 \%$ growth inhibition at the test concentrations. Contrariwise, $100 \%$ ethanol extract of A. ampeloprasum showed highest growth inhibition of $(91.6 \pm 1.3) \%$ at a concentration of $1.5625 \mu \mathrm{g} / \mathrm{ml}$. The lowest growth inhibition showed $100 \%$ ethanol extract of A. ampeloprasum was ( $44.9 \pm 0.4) \%$ at $6.25 \mu \mathrm{g} / \mathrm{ml}$ concentration, which is much higher than the maximum growth inhibition shown by other extracts against A. triticina (Fig. 1), details are provided in Table 1.

The ethanol extracts of $A$. sativum showed relatively lower antifungal activity, though $100 \%$ ethanol extract of A. sativum managed to show $50 \%$ growth inhibition at $99.17 \mu \mathrm{g} / \mathrm{ml}$ concentration of M. oryzae. $90 \%$ ethanol extract of A. sativum promoted the growth of M. oryzae at all the test concentrations, except at $3.125 \mu \mathrm{g} / \mathrm{ml}$ concentration, where it showed $(20.8 \pm 4.0) \%$ and at $1.5625 \mu \mathrm{g} / \mathrm{ml}$ concentration, where $(23.35 \pm 2.8) \%$ of growth inhibition was attained. Ethanol extracts of A. ampeloprasum, both $90 \%$ and $100 \%$, showed significantly higher antifungal activity against $M$. oryzae. The highest antifungal activity by $90 \%$ ethanol extract of A. ampeloprasum was observed at $100 \mu \mathrm{g} / \mathrm{ml}$ concentration showing ( $95.5 \pm 0.1) \%$ growth inhibition of $M$. oryzae, while the highest inhibition shown by $100 \%$ ethanol extract of A. ampeloprasum was at $12.5 \mu \mathrm{g} / \mathrm{ml}$ concentration showing $(91.3 \pm 0.3)$ $\%$ growth inhibition of M. oryzae (Fig. 2), details are provided in Table 2.

$\mathrm{MIC}_{50}$ and $\mathrm{MIC}_{90}$ values for $100 \%$ ethanol extract of $A$. ampeloprasum against $A$. triticina were observed at $1.706 \mu \mathrm{g} / \mathrm{ml}$ and $5.708 \mu \mathrm{g} / \mathrm{ml}$,

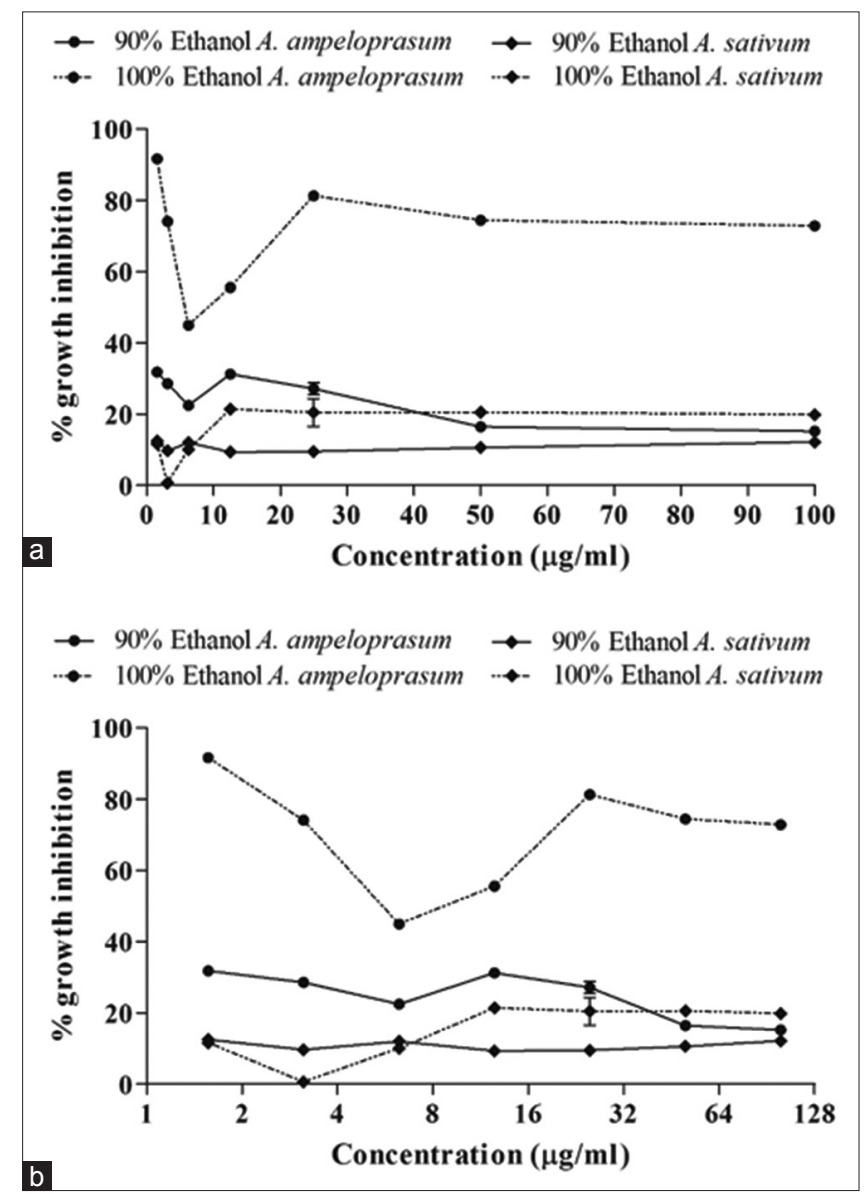

Fig. 1: Effect of the ethanol extracts on the growth of Alternaria triticina (a) lin-lin scale (b) lin-log scale (x-axis logarithmic to the base 2) 
respectively (Fig. 3). $\mathrm{MIC}_{50}$ and $\mathrm{MIC}_{90}$ values were also determined for $90 \%$ and $100 \%$ ethanol extract of $A$. ampeloprasum against M. oryzae. $\mathrm{MIC}_{50}$ was observed at $17.333 \mu \mathrm{g} / \mathrm{ml}$ for $90 \%$ ethanol extract of

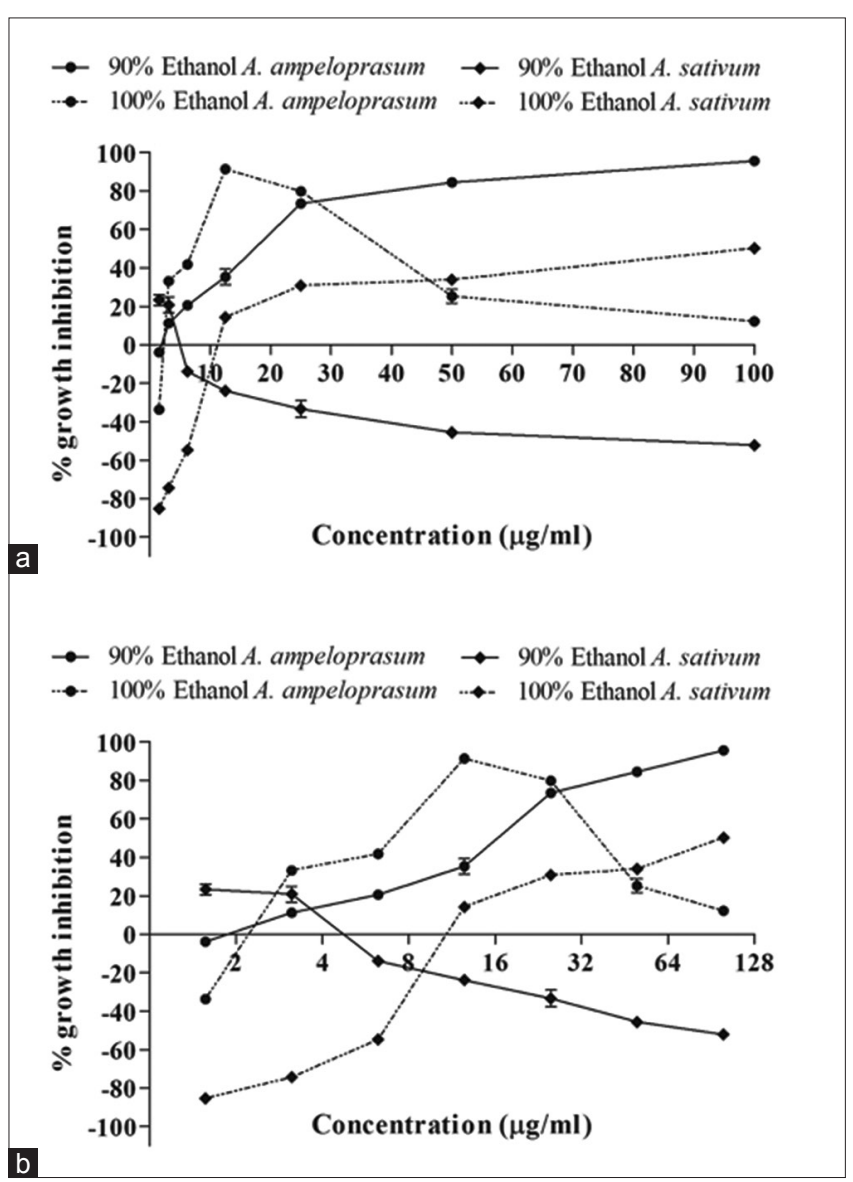

Fig. 2: Effect of ethanol extracts on the growth of Magnaporthe oryzae. (a) lin-lin scale (b) lin-log scale (x-axis logarithmic to the base 2)
A. ampeloprasum, and $\mathrm{MIC}_{90}$ was observed at $75.116 \mu \mathrm{g} / \mathrm{ml}$. Similarly, MIC $_{50}$ for $100 \%$ ethanol extract of A. ampeloprasum was observed at $7.297 \mu \mathrm{g} / \mathrm{ml}$, and $\mathrm{MIC}_{90}$ was observed at $12.336 \mu \mathrm{g} / \mathrm{ml}$ (Table 3)

The existence of antifungal activity in the extracts may be attributed to the presence of allicin which is known for its broad spectrum antifungal activity. It is a sulfur-containing compound which is responsible for the pungent smell of damaged or crushed garlic [24]. Alliin is the major compound, naturally present in garlic which is broken down into allicin, ammonium, and pyruvate under the action of alliinase enzyme [25]. Allicin is known to inhibit the germination of fungal spores as well as the hyphal growth [5]. Ajoene, another major bioactive compound of garlic might also be attributed to the antifungal property of the extracts $[6,26]$. Ajoene is known to possess much stronger antifungal activity as compared to allicin; however, it is not capable of inducing antibacterial effect [27]. Many another bioactive compound capable of inhibiting fungal growth might also be attributed to the antifungal activity of the extracts [26,28-30]. While, some extracts having poor or no inhibitory activity promoted the growth of the fungi, as seen in the case of Ipomoea extracts against Colletotrichum species [31].

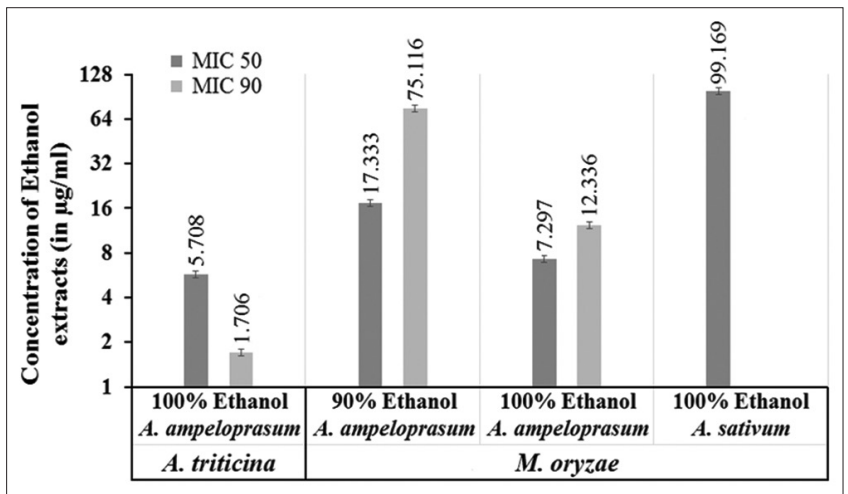

Fig. 3: Minimal inhibitory concentration ${ }_{90}$ and MIC $_{50}$ values of ethanol extracts of Allium ampeloprasum and Allium sativum at different concentrations against Alternaria triticina and Magnaporthe oryzae shown in log-lin scale (y-axis is logarithmic to base 2). Error Bar indicates a standard error of $\pm 5.0 \%$

Table 1: Antifungal activity of ethanol extracts of A. ampeloprasum and A. sativum at different concentrations against A. triticina. Growth inhibition is shown in the form of (Mean \pm SD), where $S D$ is standard deviation

\begin{tabular}{lllll}
\hline Concentration (in $\mu \mathrm{g} / \mathrm{ml})$ & $\begin{array}{l}\mathbf{9 0 \%} \text { Ethanol } \\
\text { A. ampeloprasum }\end{array}$ & $\begin{array}{l}\mathbf{9 0 \%} \text { Ethanol } \\
\text { A. sativum }\end{array}$ & $\begin{array}{l}\mathbf{1 0 0 \%} \text { Ethanol } \\
\text { A. ampeloprasum }\end{array}$ & $\begin{array}{l}\mathbf{1 0 0 \%} \text { Ethanol } \\
\text { A. sativum }\end{array}$ \\
\hline 100 & $15.20 \pm 0.4$ & $12.17 \pm 0.2$ & $72.82 \pm 1.2$ & $19.86 \pm 0.6$ \\
50 & $16.46 \pm 0.5$ & $10.58 \pm 1.4$ & $74.41 \pm 0.4$ & $20.51 \pm 1.2$ \\
25 & $27.13 \pm 1.7$ & $9.46 \pm 0.9$ & $81.21 \pm 0.7$ & $20.42 \pm 3.9$ \\
12.5 & $31.24 \pm 0.7$ & $9.28 \pm 0.3$ & $55.48 \pm 0.7$ & $21.31 \pm 0.4$ \\
6.25 & $22.47 \pm 0.9$ & $11.98 \pm 0.7$ & $44.94 \pm 0.4$ & $9.98 \pm 0.3$ \\
3.125 & $28.53 \pm 1.4$ & $9.65 \pm 0.7$ & $74.08 \pm 1.2$ & $0.65 \pm 0.3$ \\
1.5625 & $31.75 \pm 0.3$ & $12.49 \pm 0.3$ & $91.61 \pm 1.3$ & $11.61 \pm 0.4$ \\
\hline
\end{tabular}

Table 2: Antifungal activity of ethanol extracts of A. ampeloprasum and A. sativum at different concentrations against M. oryzae. Growth inhibition shown in the form of (Mean \pm SD), where SD is standard deviation

\begin{tabular}{|c|c|c|c|c|}
\hline Concentration (in $\mu \mathrm{g} / \mathrm{ml}$ ) & $\begin{array}{l}90 \% \text { Ethanol } \\
\text { A. ampeloprasum }\end{array}$ & $\begin{array}{l}90 \% \text { Ethanol } \\
\text { A. sativum }\end{array}$ & $\begin{array}{l}100 \% \text { Ethanol } \\
\text { A. ampeloprasum }\end{array}$ & $\begin{array}{l}100 \% \text { Ethanol } \\
\text { A. sativum }\end{array}$ \\
\hline 100 & $95.57 \pm 0.1$ & $-52.17 \pm 0.9$ & $12.15 \pm 1.2$ & $50.27 \pm 0.6$ \\
\hline 50 & $84.37 \pm 0.9$ & $-45.57 \pm 1.3$ & $25.26 \pm 3.6$ & $33.90 \pm 0.6$ \\
\hline 25 & $73.45 \pm 2.4$ & $-33.44 \pm 4.3$ & $79.70 \pm 1.5$ & $30.82 \pm 1.3$ \\
\hline 12.5 & $35.22 \pm 4.0$ & $-23.97 \pm 1.8$ & $91.30 \pm 0.3$ & $14.20 \pm 1.2$ \\
\hline 6.25 & $20.50 \pm 1.9$ & $-14.00 \pm 2.0$ & $41.69 \pm 1.6$ & $-54.86 \pm 1.3$ \\
\hline 3.125 & $11.16 \pm 0.9$ & $20.83 \pm 4.0$ & $33.05 \pm 2.4$ & $-74.44 \pm 0.6$ \\
\hline 1.5625 & $-3.95 \pm 1.6$ & $23.35 \pm 2.8$ & $-33.78 \pm 2.4$ & $-85.32 \pm 1.6$ \\
\hline
\end{tabular}


Table 3: $\mathrm{MIC}_{90}$ and $\mathrm{MIC}_{50}$ values of ethanol extracts of $A$. ampeloprasum and $A$. sativum at different concentrations against $A$ triticina and M. oryzae

\begin{tabular}{|c|c|c|c|c|c|}
\hline Name of fungi & MIC & $\begin{array}{l}90 \% \text { Ethanol } \\
\text { A. ampeloprasum }\end{array}$ & $\begin{array}{l}90 \% \text { Ethanol } \\
\text { A. sativum }\end{array}$ & $\begin{array}{l}100 \% \text { Ethanol } \\
\text { A. ampeloprasum }\end{array}$ & $\begin{array}{l}100 \% \text { Ethanol } \\
\text { A. sativum }\end{array}$ \\
\hline \multirow[t]{2}{*}{ A. triticina } & 90 & nd* & nd & $1.706^{*}$ & nd \\
\hline & 50 & nd & nd & 5.708 & nd \\
\hline \multirow[t]{2}{*}{ M. oryzae } & 90 & 75.116 & nd & 12.336 & 99.169 \\
\hline & 50 & 17.333 & nd & 7.297 & nd \\
\hline
\end{tabular}

*nd means not determined, concentration of ethanol extracts is in $\mu \mathrm{g} / \mathrm{ml}$

The two-way ANOVA confirmed that means of all the comparisons are significantly different, $\mathrm{p}<0.0001$ was obtained, in the case of both A. triticina and M. oryzae. Based on which, it is determined that each ethanol extract shows a different level of antifungal activity at different concentration against $A$. triticina as well as against M. oryzae.

\section{CONCLUSION}

The ethanol extracts of A. ampeloprasum showed substantial amount of antifungal activity against both fungi, sufficient enough to yield $\mathrm{MIC}_{50}$ and $\mathrm{MIC}_{90}$ values. A. triticina showed insignificant amount of inhibition in its growth when treated with ethanol extracts of $A$. sativum, in addition, $M$. oryzae showed growth, instead of inhibition, when treated with ethanol extracts of A. sativum. Therefore, it could be concluded that the ethanol extracts of $A$. ampeloprasum showed better antifungal activity against $A$. triticina as well as against $M$. oryzae as compared to the ethanol extracts of $A$. sativum. Hence, they could be used as potential fungicide, not only because of their superior antifungal property but also because of their less pungent and harmless nature against humans which is desirable of a fungicide when being used in a crop field. Further, study on the identification and extraction of pure bioactive compounds from the ethanol extracts, as well as, use of other solvents for the extraction of ethanol extracts from A. ampeloprasum could also be implemented to study the antifungal properties of $A$. ampeloprasum extensively.

\section{ACKNOWLEDGMENT}

We are grateful to the management of Lovely Professional University to provide laboratory support. We also thank Dosanjh Agricultural Research and Development Farm, Punjab, for providing garlic samples for our research.

\section{REFERENCES}

1. Block E. The chemistry of garlic and onions. Sci Am 1985;252(3):114-9.

2. Sharanappa R, Vidyasagar GM. Anti-Candida activity of medicinal plants: A review. Int J Pharm Pharm Sci 2013;5(4):9-16

3. Shivakumar PS, Vidyasagar GM. Antifungal screening of 61 traditional medicinal plants of 305 extracts against dermatophytic fungi Trichophyton tonsurans. Int J Pharm Pharm Sci 2014;7(3):186-90.

4. Corzo-Martinez M, Corzo N, Villamiel M. Biological properties of onions and garlic. Trends Food Sci Technol 2007;18(12):609-25.

5. Yamada Y, Azuma K. Evaluation of the in vitro antifungal activity of allicin. Antimicrob Agents Chemother 1977;11(4):743-9.

6. Naganawa R, Iwata N, Ishikawa K, Fukuda H, Fujino T, Suzuki A. Inhibition of microbial growth by ajoene, a sulfur-containing compound derived from garlic. Appl Environ Microbiol 1996;62(11):4238-42.

7. Irkin R, Koruklouglu M. Control of Aspergillus niger with garlic, onion and leek extracts. Afr J Biotechnol 2007;6(4):384-7.

8. Morita $\mathrm{T}$, Ushiroguchi $\mathrm{T}$, Hayashi $\mathrm{N}$, Matsuura $\mathrm{H}$, Itakura $\mathrm{Y}$, Fuwa T. Steroidal saponins from elephant garlic, bulbs of Allium ampeloprasum L. Chem Pharm Bull (Tokyo) 1988;36(9):3480-6.

9. Dey P, Khaled KL. An extensive review on Allium ampeloprasum a magical herb. Int J Sci Res 2013;4(7):371-7.

10. Kociã-Tanackov SD, Dimiã GR, Tepiã AN Vujiåiã BL. Influence of Allium ampeloprasum L. and Allium cepa $\mathrm{L}$. Essential oils on the growth of some yeasts and moulds. Zb Matice Srp Prir Nauke 2009;116:121-30.

11. Sadeghi M, Zolfaghari B, Senatore M, Lanzotti V. Antifungal cinnamic acid derivatives from Persian leek (Allium ampeloprasum Subsp.
Persicum). Phytochem Lett 2013:6(3):360-3

12. Khudhair MW, Aboud HM, Dheyab NS, Shbar AK, Khalaf HS. The first record of Alternaria triticina the causative agent of Alternaria leaf blight in wheat and barley in Iraq. Int J Phytopathol 2014;3(3):133-8.

13. Singh RN, Singh AK, Singh SP, Singh BN. Prevalence and distribution of foliar blight pathogens attacking wheat in India. Indian Phytopathol 2001;54(2):175-8

14. Dean R, VanKan JA, Pretorius ZA, Hammond-Kosack KE, Di Pietro A, Spanu PD, et al. The top 10 fungal pathogens in molecular plant pathology. Mol Plant Pathol 2012;13(7):414-30

15. Gowda M, Shirke MD, Mahesha HB, Chandarana P, Rajamani A, Chattoo BB. Genome analysis of rice-blast fungus Magnaporthe oryzae field isolates from southern India. Genom Data 2015;5:284-91.

16. Perello A, Martinez I, Molina M. First report of virulence and effects of Magnaporthe oryzae isolates causing wheat blast in Argentina. Plant Dis 2015;99(8):1177-8.

17. Fakruddin M, Mannan KS, Mazumdar RM, Afroz H. Antibacterial, antifungal and antioxidant activities of the ethanol extract of the stem bark of Clausena heptaphylla. BMC Complement Altern Med 2012;12:232.

18. Zhang L, Ravipati AS, Koyyalamudi SR, Jeong SC, Reddy N, Bartlett J, et al. Anti-fungal and anti-bacterial activities of ethanol extracts of selected traditional Chinese medicinal herbs. Asian Pac J Trop Med 2013;6(9):673-81

19. Rebaya A, Belghith SI, Hammrouni S, Maaroufi A, Ayadi MT, Chérif JK. Antibacterial and antifungal activities of ethanol extracts of Halimium halimifolium, Cistus salviifolius and Cistus monspeliensis. Int J Pharm Clin Res 2016;8(4):243-47.

20. Irkin R, Koruklouglu M. Control of some filamentous fungi and yeasts by dehydrated Allium extracts. J Verbrauch Lebensm 2009;4(1):3-6.

21. Akinmusire OO, Omomowo IO, Usman IM. Evaluation of the phytochemical properties and antifungal activities of ethanol extract of Allium sativum. Int J Curr Microbiol Appl Sci 2014;3(10):143-9.

22. Broekart WF, Terras RF, Cammune BP, Vanderleyden J. An automated quantitative assay for fungal growth inhibition. FEMS Microbiol Lett 1990;69(1-2):55-60

23. Dellavale PD, Cabrera A, Alem D, Larranga P, Ferriera F, Rizza MD. Antifungal activity of medicinal plant extracts against phytopathogenic fungus Alternaria spp. Chillán En línea 2011;71(2):231-9.

24. Borlinghaus J, Albrecht F, Gruhlke MC, Nwachukwu ID, Slusarenko AJ. Allicin: Chemistry and biological properties. Molecules 2014; 19:12591-618

25. Focke M, Feld A, Lichtenthaler K. Allicin, a naturally occurring antibiotic from garlic, specifically inhibits acetyl-CoA synthetase. FEBS Lett 1990;261:106-8.

26. Ledezma E, Apitz-Castro R. Ajoene the main active compound of garlic (Allium sativum): A new antifungal agent. Rev Iberoam Micol 2006;23(2):75-80

27. Yoshida S, Kasuga S, Hayashi N, Ushiroguchi T, Matsuura H, Nakagawa S. Antifungal activity of ajoene derived from garlic. Appl Environ Microbiol 1987;53(3):615-7.

28. Yin MC, Tsao SM. Inhibitory effect of seven Allium plants upon three Aspergillus species. Int J Food Microbiol 1999;49(1-2):49-56.

29. Lemar KM, Turner MP, Lloyd D. Garlic (Allium sativum) as an anticandida agent: A comparison of the efficacy of fresh garlic and freezedried extracts. J Appl Microbiol 2002;93(3):398-405.

30. Perello A, Noll U, Slusarenko AJ. In vitro efficacy of garlic extract to control fungal pathogens of wheat. J Med Plants Res 2013;7(24):1809-17.

31. Masangwa JI, Aveling TA, Kritzinger Q. Screening of plant extracts for antifungal activities against Colletotrichum species of common bean (Phaseolus vulgaris L.) and cowpea (Vigna unguiculata (L.) Walp). J Agric Sci 2013;151(4):482-91. 